\title{
Importing Credible Monetary Policy: A Way for Transition Economies to Fight Inflation?
}

\author{
Elham Mafi-Kreft \\ Rose-Hulman Institute of Technology \\ Steven F. Kreft* \\ Indiana University, Kelley School of Business
}

\begin{abstract}
In the 1990s, transition economies were rearranging their monetary regimes. This paper compares the chosen regimes based on the level of discretionary power and the ability to control inflation. Results show that non-discretionary regimes produce lower and more stable inflation.
\end{abstract}

JEL Classification: E58

Keywords: Transition Economies, Currency Board, European Monetary Union, Exchange Rate Regime.

\footnotetext{
* Corresponding author Steven F. Kreft: Business Economics and Public Policy, Indiana University, Kelley School of Business, 1309 East Tenth Street, Bloomington, IN 47405, Office phone: (812) 856-4965, Fax: (812) 855-3354, E-mail: skreft@indiana.edu. The authors would like to thank Russell Sobel, Jurgen von Hagen, and Michele Fratianni for their helpful comments and suggestions, and Jizhong Zhou for help in collecting pieces of our data set.
} 


\section{1- Introduction}

Following their independence in the late 1980's, almost all transition economies established a central bank to enact a national monetary policy. As mentioned by Schuler (1996), the conventional view among monetary economists was that every independent country should have its own central bank in order to conduct independent monetary policy. In contrast, around the time of the independence movement, eleven countries gave up their monetary sovereignty to the European Central Bank. Clearly the real difference in these two movements revolves around the degree of discretionary monetary policy.

The aim of this paper is to test whether transition economies with nondiscretionary monetary regimes, i.e. hard pegs, (defined as adopting a currency board or maintaining a de facto exchange rate peg) experience more stable and lower inflation than the transition economies with discretionary regimes, i.e. flexible regimes, (defined as having flexible exchange rates). These definitions are developed from the exchange rate regime flexibility index of Bubula and Otker-Robe (2002), which assigns values from 1 to 13, where we consider 1-4 as hard peg regimes and 5-13 as flexible regimes. We also test to see whether transition economies that are on the fast track to join the European Monetary Union (EMU) experience lower levels of inflation. ${ }^{1}$

\section{2-Panel Analysis of the Determinants of Inflation}

The contribution of this paper is that it is the first to explicitly focus on the transition countries' ability to maintain stable and low inflation by comparing the structure of their

\footnotetext{
${ }^{1}$ We define countries being on the 'fast track' to join the EMU as those countries that joined the European Union in 2004.
} 
monetary institutions. For general comparison we conduct a difference in mean and difference in variance test for the inflation of two groups of transition economies: (i) hard peg regimes and (ii) flexible regimes, over the time period 1995-2001. ${ }^{2}$ The results reported in Table 1 show that the hard peg regimes experienced significantly less volatile and lower inflation when compared to the flexible regimes.

\section{[Table 1 about here]}

Looking at Table 1, it is evident that our sample is characterized by high variance and high overall inflation. We want to conduct a study of the impact that monetary regimes have on inflation, but our analysis might be biased by the high variation in inflation. Following Cukierman, Miller, and Neyapti (2002) we correct for this potential bias by capturing inflation as the rate of depreciation in the real value of money. Table 1 also contains the difference in mean and difference in variance test for the rate of depreciation in the real value of money and results are identical to those using inflation.

To further analyze the impact of monetary regimes, we collected panel data on twenty-five transition economies, from 1995-2001, and our analysis builds off of the standard model of inflation. We expect that the transition economies with hard peg regimes will better control inflation. Testing the effect of hard peg regimes, will serve as a robustness check to the findings of Bleaney and Francisco (2003), which analyzes developing countries, excluding those in transition, and finds hard pegs reduce inflation.

Also, we propose that being on the fast track to join the EMU may produce more disciplined policies, as the countries have to meet certain convergence criteria. This case

\footnotetext{
${ }^{2}$ The inflation data come from the IMF and included twenty-six IMF classified transition economies, six of which had hard peg regimes.
} 
is interesting because it does not involve an "institutional" change, but more of a change in the self-discipline of the government. For example, Rogoff (1985) and Hanke and Schuler (1994) have documented how non-institutional factors can influence inflation. However, it could also be that the fast track to join the EMU may not significantly impact inflation in transition economies, because it is only an announcement to join at a later date, and may not significantly tie the hands of the monetary authority.

To examine the determinants of inflation as measured by the rate of depreciation in the real value of money, we estimate a panel regression that takes the following general form: ${ }^{3}$

$$
D_{i t}=M_{i t}^{\prime} \beta_{1}+X_{i t}^{\prime} \beta_{2}+C_{i}+\varepsilon_{i t} i=1, \ldots, N \text { and } t=1, \ldots, T
$$

Where D stands for the rate of depreciation in the real value of money of country i at time $t, t$ denotes years from 1995 to 2001, $\beta_{1}$ and $\beta_{2}$ are vectors of parameters to be estimated, $\mathrm{M}$ is a vector of monetary regime indicators, $\mathrm{X}$ is a vector of control variables that closely conforms to what has been previously used in the literature, C are the fixed effects for each country, and $\varepsilon$ is the error term.

We include four monetary regime indicators, where the first indicator is standard in the previous literature, and the following three indicators are our contribution to the model of transition economies. ${ }^{4}$ First, we include the index of legal central bank independence, developed by Cukierman, Miller, and Neyapti (2002). This index is

\footnotetext{
${ }^{3}$ All data are from the CIA World Fact Book and the World Bank’s World Development Indicators Database.

${ }^{4}$ Choice of the monetary regime is taken as exogenous following Hanke (2000) and Fatas and Rose (2001).
} 
expected to carry a negative sign because increased independence implies that the central bank is less exposed to seigniorage pressure, and thus may experience lower inflation. Second, we include the Bubula and Otker-Robe (2002) exchange rate flexibility index, which is expected to carry a positive sign, showing that when discretion is increased, inflation will be higher. Third, we include a control dummy for the years in which a country had a hard peg regime, which is expected to carry a negative sign, showing that hard pegs lead to lower inflation. Last, we include a dummy variable for the countries on the fast track to join the EMU, which is expected to carry a negative sign, to show that the being on the 'fast track' can act as a non-institutional limitation on discretionary policy and lead to less inflation.

We include four control variables closely based on the literature for modeling inflation that capture fiscal, economic, and structural influences. First, the government fiscal balance as a percentage of GDP is expected to carry a positive sign because of the assumption that fiscal motives drive inflation pressures. Second, according to the economic literature on inflation and economic growth, such as Fisher, Sahay, and Vegh (2002) there is an inverse relation between economic growth and inflation. However, the causal relation is not agreed upon, so the annual real GDP growth rate is treated as endogenous and is expected to carry a negative sign. Third, the country's openness to trade, measured as a country's imports plus exports as a percentage of GDP, could potentially carry a positive or negative sign as the current literature is somewhat divergent. Romer (1993) has found a negative relationship; however, Bleaney (1999) argues that the once robust negative relationship between openness and inflation is disappearing in the 1990's. Last, the share of the value added of agriculture in GDP is 
expected to carry a positive sign based on the arguments of Cukierman, Edwards, and Tabellini (1992) that the agricultural sector is difficult to tax. Following this logic, the countries with more pronounced agricultural sectors, may rely more on seigniorage, which may lead to higher inflation.

[Table 2 about here]

The estimated determinants of the rate of depreciation in the real value of money are presented in Table $2 .^{5}$ Note that the regression specifications differ by the included monetary regime indicators. ${ }^{6}$ Our base model seems to fit the data well, as our R-squared measure remained around 0.78 . Also, the control variables all retained the expected signs and had varying degrees of significance.

The variables of interest in our analysis are the monetary regime indicators. The previous literature's model of inflation is found in specification [a], which includes the control variables as well as the central bank independence measure. Central bank independence is found to be significant in all specifications that it was included and of the expected negative sign. We then build on this base regression by adding the other three monetary regime indicators in various combinations.

The Bubula and Otker-Robe (2002) exchange rate flexibility index was positive and significant at the $1 \%$ level in specifications [b] and [c], the specifications without the hard peg control. This shows that increases in the degree of exchange rate flexibility will

\footnotetext{
${ }^{5}$ All regression specifications included country fixed effects, which are available upon request to the authors. Also, regressions were estimated with year fixed effects, and results remained virtually unchanged. ${ }^{6}$ Specifications [f], [g], and [h] include both the hard peg indicator and exchange rate flexibility index, this is done to test if the exchange rate regime flexibility index has any explanatory power after the hard peg regimes are accounted for.
} 
result in higher inflation. However, the exchange rate regime flexibility index is significant at only the $10 \%$ level in specification [f] and lost its significance in specifications [g] and [h], the specifications with the hard peg control. This confirms the findings of Bleaney and Francisco (2003) that only hard pegs impact inflation.

The hard peg control was negative and significant at the $1 \%$ level in specifications [d] and [e], the specifications without the exchange rate regime flexibility index. This result implies that countries with hard pegs experience significantly less inflation relative to countries that have flexible regimes. Furthermore, the hard peg control retained its negative sign and was significant at the $5 \%$ and $1 \%$ level in specifications [f], [g], and [h], the specifications that included the exchange rate regime flexibility index. Again this result confirms the hypothesis that only hard pegs matter.

The fast track to join the EMU had the expected negative sign and the estimated coefficient was found to be significantly different from zero in three of the four specifications in which it was included. The one specification that the fast track lost its significance, was specification [d], which did not include the exchange rate flexibility index. Overall, our results imply that being on the fast track to join the EMU, a noninstitutional regime change, significantly lowers inflation.

Interpreting the impact of our monetary regime indicators reveals that adopting a hard peg, along with having an independent central bank, is the most effective way to fight inflation. Our results indicate that transition countries with hard peg regimes will on average experience less depreciation of real value of money by 0.201 relative to flexible regimes. Also, we find that raising the central independence index by one degree will on average lesson the depreciation of real money by 0.187 . Furthermore, our results show 
that whenever a country's exchange rate flexibility index is increased by one degree of flexibility, the country will on average experience more depreciation of real money by 0.015 , and likewise decreasing flexibility will lower the rate of depreciation of real money. Finally, our results reveal that those transition countries that are on the fast track to join the EMU, on average experience less depreciation of real value of money by 0.069 relative to those countries not on the fast track.

\section{3- Conclusion}

This paper strongly advocates that changes in monetary regimes towards those that limit discretionary power are necessary to significantly impact inflation in transition economies. Our results suggest that transition economies that replace existing central banking regimes with a hard peg regime should experience lower inflation. This study helps to strengthen the existing literature on the benefits of adopting hard pegs, as these arrangements appear to be effective institutions to discipline monetary policy. 


\section{References}

Bubula, A. and I. Otker-Robe (2002) “The Evolution of Exchange Rate Regimes Since 1990: Evidence from de Facto Policies” IMF Working Paper No. 02/155

Bleaney, M (1999) “The Disappearing Openness-Inflation Relationship: A CrossCountry Analysis of Inflation Rates” IMF Working Papers, WP/99/161

Bleaney, M. and M. Francisco (2003) "Exchange Rate Regimes and Monetary Discipline: Only Hard Pegs Make a Difference” University of Nottingham, School of Economics Discussion Papers \#03/15.

Cukierman, A., S. Edwards, and G. Tabellini (1992) “Seigniorage and Political Instability” American Economic Review, v.82, pp.537-555.

Cukierman, A., G. Miller, and B. Neyapti. (2002) “Central Bank Reform, Liberalization and Inflation in Transition Economies- An International Perspective” Journal of Monetary Economics, v49, pp.237-264.

Fatas, A. and A.K. Rose (2001) "Do Monetary Handcuffs restrain Leviathan? Fiscal Policy in Extreme Exchange Rate Regimes” IMF Staff Papers: Special Issue, v.47, pp.40-61.

Fisher, S., R. Sahay, and C. Vegh (2002) “Modern Hyper- and High Inflations” Journal of Economic Literature, v40, pp.837-880.

Hanke, S., and K. Schuler.(1994) "Financial Reform and Economic Development: The Currency Board System for Eastern Europe” in Boettke (ed.) The Collapse of Development Planning, New York and London, New York University Press.

Hanke, S. (2000) “The Disregard for Currency Boards Realities” The Cato Journal, v20, pp.49-59.

Rogoff, K. (1985) “The Optimal Commitment to an Intermediate Monetary Target” Quarterly Journal of Economics, v.100 pp.1169-1189.

Romer, D. (1993) “Openess and Inflation: Theory and Evidence” Quarterly Journal of Economics, v108, pp.869-903.

Schuler, K. (1996) Should Developing Countries Have Central Banks? Currency Quality and Monetary Systems in 155 Countries, London, Institute of Economics Affairs. 
Table 1: Difference in Mean and Difference in Variance Tests (1995-2001)

\begin{tabular}{|c|c|c|}
\hline Inflation & Mean & Variance \\
\hline Flexible Regime & 93.43 & 8332.46 \\
\hline Hard Peg Regime & 11.31 & 239.21 \\
\hline Flexible Regime_-Hard Peg Regime & $82.12^{\star \star \star}$ & $8093.25^{\star \star \star}$ \\
\hline Statistical Difference Test & $t=3.93$ & $F=34.83$ \\
\hline Rate of Depreciation in the Real Value of Money & Mean & Variance \\
\hline Flexible Regime & 0.24 & 0.02 \\
\hline Hard Peg Regime & 0.09 & 0.01 \\
\hline Flexible Regime_-Hard Peg Regime & $0.15^{\star \star \star}$ & $0.01^{\star *}$ \\
\hline Statistical Difference Test & $t=2.96$ & $F=2.81$ \\
\hline
\end{tabular}


Table 2: Determinants of the Depreciation in the Real Value of Money (1995-2001)

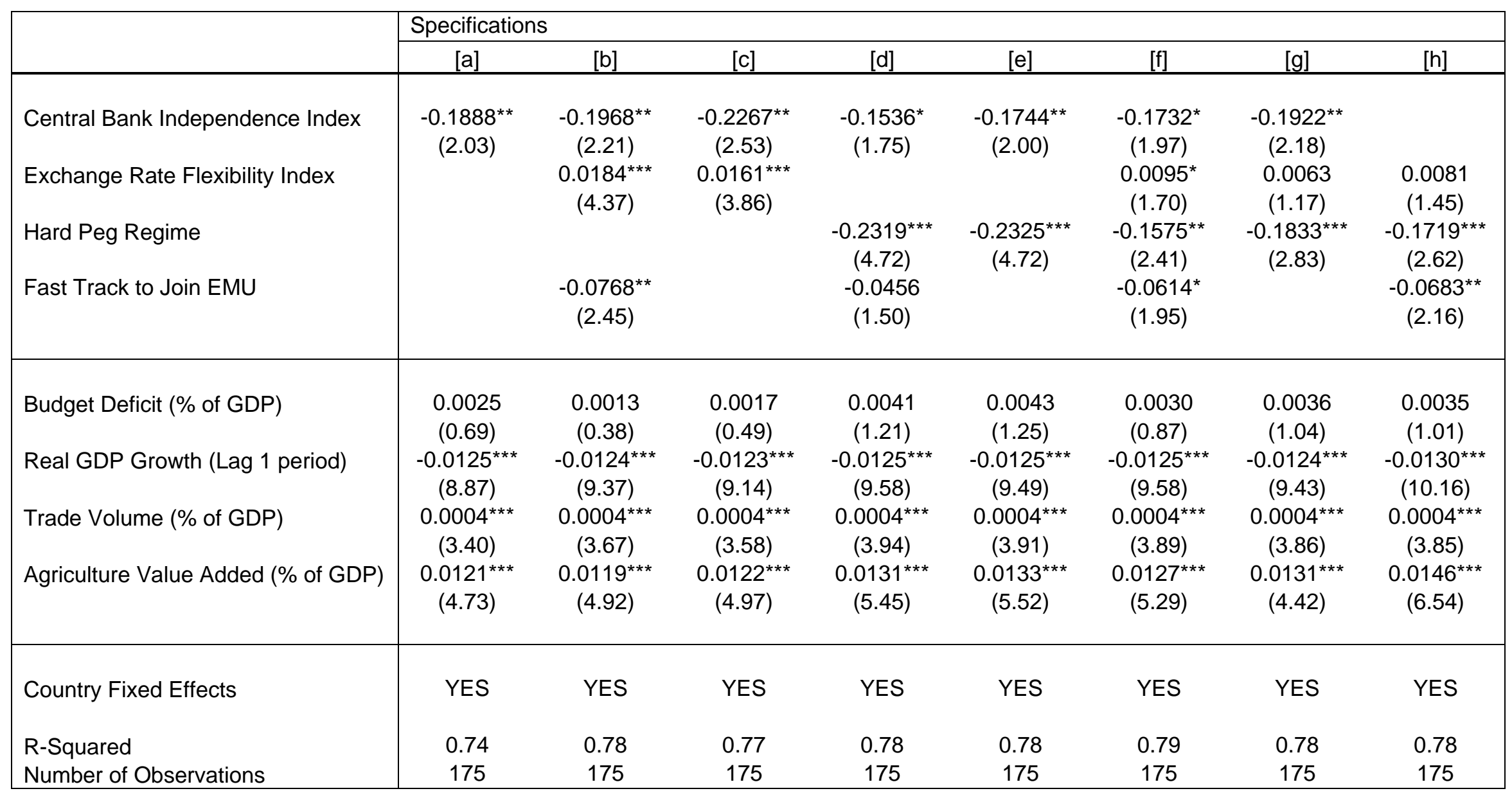

Notes: Absolute t-ratios in parenthesis, the exchange rate flexibility index is from Bubula and Otker-Robe (2002), the independence of central bank index is from Cukierman, Miller, and Neyapti (2002), and estimated country fixed effects available upon request to the authors. Significance levels are represented by: ${ }^{* * *} 1 \%,{ }^{* *} 5 \%,{ }^{*} 10 \%$ 